\section{Creutzfeldt-Jakob disease and bovine spongiform encephalopathy}

Magnetic resonance imaging may have a role in diagnosing Creutzfeldt-Jakob disease

EdrToR,-Creutzfeldt-Jakob disease' is still rarely diagnosed in Britain, and neuropathological examination is required to confirm the diagnosis. Research in the United States, however, has shown the presence of bilaterally symmetric hyperintense abnormalities in the basal ganglia in T2 weighted magnetic resonance images in patients with pathologically proved Creutzfeldt-Jakob disease. ${ }^{2}$ This abnormality on magnetic resonance imaging was first reported in $1988 .{ }^{3} \mathrm{~A}$ colleague and I have reported Creutzfeldt-Jakob disease, with signal abnormalities in the basal ganglia on magnetic resonance imaging, in a 58 year old man with no occupational exposure to animals who presented with progressive dementia. ${ }^{4}$

The prevalence of hyperintense abnormalities in the basal ganglia in T2 weighted images in patients with Creutzfeldt-Jakob disease has not been studied and remains unknown. Such hyperintense abnormalities in the basal ganglia can be seen in several disorders, but a combination of clinical features, laboratory findings, and imaging characteristics can be used to distinguish the other conditions from Creutzfeldt-Jakob disease. Although the absence of bilateral symmetric hyperintense lesions in the basal ganglia does not exclude Creutzfeldt-Jakob disease, it is reasonable to assume that their presence in patients with rapidly progressive dementia is a specific sign of the disease. It would be useful to know of other documented cases in which magnetic resonance imaging was carried out before death. Surely it would be worth while pursuing further research in this field and collating data from several centres with an interest in Creutzfeldt-Jakob disease to evaluate the role of magnetic resonance imaging in this condition.

TERENCE FEATHERSTON Consultant radiologis

Department of Radiology, Darlington Memorial Hospital,

Darlington DL3 6HX

1 Almond JW, Brown P, Gore SM, Hofman A, Wientiens DPWM Ridley RM, et al. Will bovine spongiform encephalopathy transmit to humans? $B M F$ 1995;311:1415-21. (25 November.)

2 Barboriak DP, Provenzale JM, Boyko OB. MR diagnosis of Creutzfeldt-Jakob disease: significance of high signal intensity of the basal ganglia. $A \not R R$ 1994;162:137-40.

3 Gertz HJ, Henkes H, Cervos-Navarro J. Creutzfeldt-Jakob disease: correlation of MRI and neuropathologic findings. Neurology 1988;38:1481-2

4 Featherstone $T$, Weerasinghe $S$. Creutzfeldt-Jakob disease-can MRI help in diagnosis? International fournal of Geriatric Psychiatry (in press).

\section{Aetiology of scrapie in certain circumstances is not evidence against another aetiology in different circumstances}

EdToR,-We are pleased that, in the commentary on our article on the myth of maternal transmission of spongiform encephalopathy, R G Will agrees that maternal transmission does not occur in human or experimental forms of spongiform encephalopathy and that the only circumstance in

\section{Advice to authors}

We receive more letters than we can publish: we can currently accept only about one third. We prefer short letters that relate to articles published within the past four weeks. Letters received after this deadline stand less chance of acceptance. We also publish some "out of the blue" letters, which usually relate to matters of public policy.

When deciding which letters to publish we favour originality, assertions supported by data or by citation, and a clear prose style. Wit, passion, and personal experience also have their place.

Letters should have fewer than 400 words and no more than five references (including one to the $\mathrm{BMJ}$ article to which they relate); references should be in the Vancouver style. We welcome pictures.

Letters should be typed and signed by each author, and each author's current appointment and address should be stated. We encourage you to declare any conflict of interest.

Please enclose a stamped addressed envelope if you would like to know whether your letter has been accepted or rejected.

Letters will be edited and may be shortened.

which it requires serious consideration is natural scrapie.'

The genetics of natural scrapie and the genetics of susceptibility to experimental transmission of scrapie in sheep differ. The characteristics and quantity of the agent, the route of exposure, and the interaction between the host genotype and the strain of agent are known only for, or are relevant only to, experimental transmission; in some cases they apply only to the laboratory disease in rodents. Data on experimental transmission are therefore of only limited relevance to natural scrapie.

The occurrence of scrapie in two of 20 Suffolk sheep exported from New Zealand in the 1960s is interesting, but, obviously, if New Zealand were free of scrapie at that time then these two animals could not have acquired scrapie by maternal transmission or other perinatal events. Care should be taken, however, in interpreting these data, since the scrapie free status of New Zealand applies to the 70 million strong national sheep flock, which is based largely on English Romneys, Lincolns, Southdowns, and sub-breeds of Merinos. ${ }^{2}$ Natural scrapie has rarely if ever been recorded in these breeds. ${ }^{3}$ The number of Suffolks in New Zealand is extremely small, and all the cases of scrapie in New Zealand have occurred in Suffolks. ${ }^{4}$ Similarly, almost all the outbreaks of scrapie in Canada, the United States, and Australia have been in Suffolks. ${ }^{5}$

The point of our article is that there is no evidence for maternal transmission of any form of spongiform encephalopathy and that the epidemiology of natural scrapie is adequately explained by the sheep genotype. Spongiform encephalopathy is undoubtedly transmissible, and knowledge of the circumstances in which transmission occurs is extremely important both for the control of the disease in animals and for the prevention of disease in humans, especially since, in the West, all known acquired cases in humans have been iatrogenic.
But a better understanding of the disease process is achieved when it is recognised that cases are either idiopathic or acquired and that evidence for one aetiology in certain circumstances is not evidence against another aetiology in different circumstances.

R M RIDLEY gnition team H F BAKER Senior scientific officer

Department of Experimental Psychology, Cambridge University, Cambridge CB2 3EB

1 Ridley RM, Baker HF. The myth of maternal transmission of spongiform encephalopathy. BMf 1995;311:1071-6. [With commentary by $\mathrm{R} G$ Will.] (21 October.)

2 Bruere AN. Scrapie: a point of view. New Zealand Veterinar fournal 1977;25:259-60.

3 Parry HB. Scrapie disease in sheep; historical, clinical, epidemiological and practical aspects of the natural disease. London Academic Press, 1983.

4 Brash AG. Scrapie in imported sheep in New Zealand. New Zealand Veterinary fournal 1952;1:27-30.

5 Hourrigan JL, Klingsporn A, Clark WW, de Camp M. Epidemiology of scrapie in the United States. In: Prusiner SB, demiology WI scrapis in the Unird system. Vol. 1. New York: Academic Press, 1979:331-56.

\section{Bovine spongiform encephalopathy is being maintained by vertical and horizontal transmission}

EDITOR,-In their article looking at the possibility of maternal transmission of spongiform encephalopathy R M Ridley and H F Baker analyse previously published information and conclude that natural sheep scrapie has a genetic basis. ${ }^{1}$ Of course this is so. Because of the absence of nucleic acid within the infective particle, host genome is required for the pathogenesis of the disease, ${ }^{2}$ and it follows that such genes are inherited in various ways. This in no way negates the well established observations that the transmissible spongiform encephalopathies are due to infectious agents which are acquired by vulnerable hosts in a variety of ways, including maternal transmission. ${ }^{3}$ Maternal transmission cannot sustain the disease in a species in the long term, but it will occur in association with horizontal transmission due, for example, to several lambs or ewes eating or having contact with an infected placenta. ${ }^{4}$

Ridley and Baker omit to provide any of the evidence supporting the occurrence of vertical and horizontal transmission of the infectious agent for bovine spongiform encephalopathy under farm conditions. This evidence includes the following.

By early 1989 bovine spongiform encephalopathy had been carefully studied for three years, and it was predicted that the total number of cases would be $17000-20000$, on the assumption that neither vertical nor horizontal transmission occurred. ${ }^{5}$ By 26 October 1995 the number of cases of bovine spongiform encephalopathy that had been confirmed in the United Kingdom was $154150 .^{6}$

Because of the belief that recycled animal remains was the cause of bovine spongiform encephalopathy ${ }^{5}$ this practice was made illegal from 18 July 1988 after extensive consultation. Indeed, in early 1989 this ban was considered to have been implemented effectively. ${ }^{5}$ From September 1988 to April 1989, newborn calves were removed from 600 dams by the Ministry of Agriculture, Fisheries and Food and were reared on fresh grass so that the extent, if any, of vertical transfer could be quantified.' By January 1995 more than 30 of 